Article

\title{
Towards a Baseline for Food-Waste Quantification in the Hospitality Sector-Quantities and Data Processing Criteria
}

\author{
Christopher Malefors ${ }^{1, * \mathbb{D}}$, Pieter Callewaert ${ }^{2}$, Per-Anders Hansson ${ }^{1}$, Hanna Hartikainen ${ }^{3}$, \\ Oona Pietiläinen ${ }^{3}$, Ingrid Strid ${ }^{1}$, Christina Strotmann ${ }^{4}$ (i) and Mattias Eriksson ${ }^{1(D)}$ \\ 1 Department of Energy and Technology, Swedish University of Agricultural Science, Box 7032, \\ SE-75007 Uppsala, Sweden \\ 2 Ostfold Research, Stadion 4, 1671 Krakeroy, Norway \\ 3 Natural Resources Institute Finland, Maarintie 6, FI-02150 Otaniemi, Finland \\ 4 Institute of Sustainable Nutrition, Muenster University of Applied Sciences, Corrensstr. 25, \\ 48149 Münster, Germany \\ * Correspondence: christopher.malefors@slu.se; Tel.: +46-(0)18-67-18-16
}

Received: 29 May 2019; Accepted: 25 June 2019; Published: 27 June 2019

check for updates

\begin{abstract}
There is an urgent need for primary data collection on food waste to obtain solid quantification data that can be used as an indicator in the goal of halving food waste by 2030 . This study examined how quality baselines for food waste can be achieved within the different segments of the hospitality sector, encompassing establishments such as canteens, elderly care units, hospitals, hotels, preschools, primary schools, restaurants, and upper secondary schools. The empirical material comprised food-waste quantification data measured in 1189 kitchens in Sweden, Norway, Finland, and Germany for 58,812 quantification days and 23 million portions. All the data were converted to a common format for analysis. According to the findings, around 20\% of food served became waste. Waste per portion varied widely between establishments, ranging from $50.1 \pm 9.4 \mathrm{~g} /$ portion for canteens to $192 \pm 30 \mathrm{~g} /$ portion for restaurants. To identify the measurement precision needed for tracking changes over time, we suggest statistical measures that could be used in future studies or in different food-waste tracking initiatives.
\end{abstract}

Keywords: quantification; baseline; sustainable development goals; benchmark; waste per portion; restaurants; hotels; schools; measurements

\section{Introduction}

Issues relating to food waste have attracted significant attention in recent years, but there seems to be no obvious all-round solution for dealing with these issues. On a global level, it is estimated that one third of the food produced for human consumption, corresponding to roughly 1.3 billion tons per year, is wasted at some point. These vast volumes have a significant environmental impact, since resources such as land, water, and energy associated with the different stages of food production and supply chain are used in vain. There is also an asymmetry regarding food losses and waste within the food production chain, with developed countries being more inclined to waste food later in the supply chain, whereas food waste in developing countries occurs early in the food chain [1]. On top of these aspects, there is also the ethical and moral problem of the severe imbalance between surplus food suitable for human consumption being wasted in the developed countries [2] while people in poverty locally or in societies in countries or regions suffering from famine have insufficient food [3]. However, political and global communities have started to address the challenges associated with food waste. In 2015, the topic was brought to the attention of world leaders when it became one of the targets of 
the United Nations (UN) Sustainable Development Goals (SDGs) for 2030. The target itself aims to: "By 2030, halve per capita global food waste at the retail and consumer level and reduce food losses along production and supply chains, including post-harvest losses" [4]. The European Union (EU) has committed to this goal [5], and other initiatives have been taken simultaneously to cut food waste on various levels and with different methods and ambitions [6]. There is also a suggestion that the ambition set by UN is not strict enough and that further food-waste reductions need to be achieved in order to keep the planet within the planetary boundaries and counter climate change [7].

To approach and achieve the global directive to reduce food waste and overcome the structural problem of food waste, it is necessary to gain insights into where, why, and how much food and/or inedible associated parts are removed from the food supply chain [8]. The UN's Food and Agriculture Organization (FAO) has recently released a methodology for monitoring food losses on global level in the supply chain [9], while an equivalent version covering the retail and consumer part of SDG 12.3 with a food-waste index is still under development. However, there are several standards and frameworks that can provide insights about the food-waste situation on global and local level and also promote consistency and transparency in food-waste quantification [10]. The use of standards and frameworks can help identify hotspots with the greatest potential for waste reduction, thus providing users with indications on where to take action and guiding further work [11].

Moreover, use of a standardized framework and its output in terms of quantification data can help establish baselines, against which measures intended to reduce food waste can be evaluated to determine whether they give the appropriate reduction in food waste [12]. Establishing baselines for food-waste quantification in order to identify problems has been identified as a vital step in waste reduction [13]. Clear baselines would also make it possible for different actors to compare, communicate, and benchmark different results with each other and within the community. Knowledge of effective measures can be spread and shared between actors sharing similar features and organizational characteristics, or used to overcome unique problems.

The hospitality sector has been identified as a sector with great potential for food-waste reduction [14-16]. The sector includes actors within the food system that provide food in establishments such as restaurants, hotels, canteens, and catering. In a food system perspective, the hospitality sector is complex in that it has a plethora of actors ranging from small privately owned restaurants on street corners to global chains present in almost all countries of the world. The range of actors within the sector, the type of target groups they serve, and the conditions in which they operate give rise to different waste generation patterns $[17,18]$. For instance, the portion size provided by a typical preschool in Sweden differs from that served by a tourist hotel in Saudi Arabia [19]. The kinds of meals served within the hotel segment of the hospitality sector also differ, e.g., some hotels do not serve any meals, some only breakfast, and some serve breakfast, lunch, and dinner, and provide bar food. Previous quantifications of food waste within the different segments of the hospitality sector are summarized in Table 1.

Table 1. Food-waste quantification results from previous studies, expressed as "Waste (\%) of food served".

\begin{tabular}{|c|c|c|c|c|c|c|}
\hline Kitchen Type & Country & Kitchen Units & $\begin{array}{c}\text { Quantification } \\
\text { Length }\end{array}$ & $\begin{array}{l}\text { Waste }(\%) \text { of } \\
\text { Food Served }\end{array}$ & $\begin{array}{c}\text { Waste/Portion } \\
\text { (g) }\end{array}$ & \\
\hline Preschool & USA & 1 & 5 days & 45.3 & 210 & [20] \\
\hline Hospital & UK & 1 & 28 days & $>40$ & - & [21] \\
\hline Hospital & UK & 3 & 2 days & $19-66$ & - & [22] \\
\hline Catering & Egypt & - & - & $23-51$ & $126,131,166$ & [23] \\
\hline Hospital & Portugal & 1 & 8 weeks & 35 & 953 & [24] \\
\hline Schools & Portugal & 21 & 1 month & 27.5 & 49.5 & [25] \\
\hline Schools & Italy & $4-5$ & 5-10 days & 27 & - & [26] \\
\hline $\begin{array}{l}\text { Hospitality and } \\
\text { catering sector }\end{array}$ & Finland & 72 & 1 day-1 week & $8-27$ & - & [27] \\
\hline
\end{tabular}


Table 1. Cont.

\begin{tabular}{ccccccc}
\hline Kitchen Type & Country & Kitchen Units & $\begin{array}{c}\text { Quantification } \\
\text { Length }\end{array}$ & $\begin{array}{c}\text { Waste (\%) of } \\
\text { Food Served }\end{array}$ & $\begin{array}{c}\text { Waste/Portion } \\
\text { (g) }\end{array}$ & \\
\hline University & Portugal & 1 & 4 weeks & 24 & 280 & {$[28]$} \\
Public sector & Sweden & 30 & 3 months & $23(13-34)$ & $75(33-131)$ & {$[14]$} \\
Schools & China & 6 & 1 day/unit & 21 & 130 & {$[29]$} \\
Schools and & Sweden & 4 & 2 days & 20 & 92.5 & {$[30]$} \\
restaurants & Italy & 3 & $92+33$ days & 15.31 & - & {$[31]$} \\
$\quad$ Schools & Switzerland & 2 & 5 days & 7.69 and 10.73 & 86 and 91 & {$[32]$} \\
Schools and & Sweden & 4 & 2 weeks & - & 145 & {$[33]$} \\
Restaurants & Turkey & 3 & 3 weeks & & $61.7(48.5-75.2)$ & {$[34]$} \\
Preschool & & & & & &
\end{tabular}

Although much research has already been performed within a few industrialized countries [35], primary data are badly needed. The studies performed so far have used a relatively small number of quantification days and have had different aims and methods, making it difficult to compare the results. Higher-resolution data covering different segments of the hospitality sector are needed to put these previous findings into perspective. There is therefore an urgent need for a systematic method to examine how different segments of the hospitality sector perform and establish more useful reference points for further food-waste reduction efforts.

The aims of the present study were to evaluate how much food waste is generated within the different segments of the hospitality sector and to develop a method for quantifying waste and comparing the different segments using available data. The focus was on the "big picture", rather than on detailed descriptions of segments, to create a foundation for further food-waste reduction actions and evaluations that can provide a robust and representative baseline. Hence, key performance indicators to monitor food waste were assessed and attempts were made to identify indicators of data quality and the desired level of data.

\section{Materials and Methods}

It is essential to define the hospitality sector and its constituent segments. The Nordic Council of Ministers [17] defines the hospitality sector as comprising actors such as restaurants, hotels, canteens, and catering establishments. This sector is commonly split into profit and cost sub-sectors according to the British organization Waste and Resources Action Program (WRAP) [36]. The profit sub-sector consists of hotels, guesthouses, restaurants, cafés, canteens, catering, convenience stores, and pubs/bars (Horeca), while the cost sub-sector consists of businesses where providing hospitality services is not the main focus and where the aim is not to maximize profit, such as catering and accommodation services within schools, universities, hospitals, nursing homes, prisons, military facilities, staff canteens, etc. [36]. However, there are a plethora of different types of kitchens operating under different conditions, making the boundaries unclear and with overlap between the different kinds of actors. This study focuses on restaurants, hotels, canteens, and catering units in schools, universities, hospitals, nursing homes, and companies, across the profit and cost sub-sectors within the hospitality sector. Prisons and military facilities are not included.

To achieve transparent food-waste quantification, it is necessary to define clearly the waste arising from each kitchen process. In this study, definitions for the different waste processes (Table 2) used by the Swedish National Food Agency [37], together with the process definitions identified by Eriksson [38] are used. However, waste processes alone are not sufficient indicators, and other indicators, such as amount of food served, need to be identified and defined. 
Table 2. Definitions used in the food-waste quantification process.

\begin{tabular}{|c|c|}
\hline Name & Definitions \\
\hline \multicolumn{2}{|l|}{ Waste process } \\
\hline Receiving waste & $\begin{array}{l}\text { Waste that occurs from goods delivered to the kitchen, but never stored or used. Also known as } \\
\text { reclamation waste in other sectors, such as retail. }\end{array}$ \\
\hline Storage waste & Stored goods that become waste for whatever reason. \\
\hline Preparation waste & Waste from the preparation and/or trimming of food, such as peel, bones, and fat. \\
\hline Safety margin waste & $\begin{array}{l}\text { Waste from food produced which did not leave the kitchen for consumption and was not saved for } \\
\text { another meal. }\end{array}$ \\
\hline Serving waste & Food served that did not reach the plates of guests. \\
\hline Plate waste & All waste from the plates of guests. May contain napkins and/or bones. \\
\hline Waste & $\begin{array}{l}\text { Sum of mass from the different food-waste processes. Used for calculation of key performance } \\
\text { indicators (KPIs) for food-waste quantification baselines. }\end{array}$ \\
\hline Served food & The amount of food that left the kitchen intended for consumption. \\
\hline Portions & $\begin{array}{l}\text { The recorded number of portions served for a given meal. One portion is defined as the amount } \\
\text { one person eats per meal. }\end{array}$ \\
\hline Meal & Breakfast, lunch, dinner, or snack, depending on when the food is served. \\
\hline \multicolumn{2}{|r|}{ 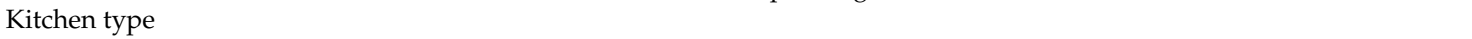 } \\
\hline Production unit & A kitchen that prepares all meals from raw materials. \\
\hline Satellite kitchen & $\begin{array}{l}\text { Kitchen that can prepare some meals, but relies on deliveries from a production unit, especially for } \\
\text { food that needs to be cooked. }\end{array}$ \\
\hline KPI & Key performance indicator. \\
\hline Waste/portion (g) & Waste $(\mathrm{kg})$ divided by the number of portions $\times 1000$. \\
\hline Waste $(\%)$ & Waste $(\mathrm{kg})$ divided by served food $(\mathrm{kg}) \times 100$. \\
\hline
\end{tabular}

Past food-waste studies seldom include all waste processes within a kitchen establishment. The most commonly included processes are "Plate waste", "Serving waste", and "Preparation waste" [26,39]. Figure 1 sets the different definitions in Table 2 in context and indicates where the different waste processes usually occur.

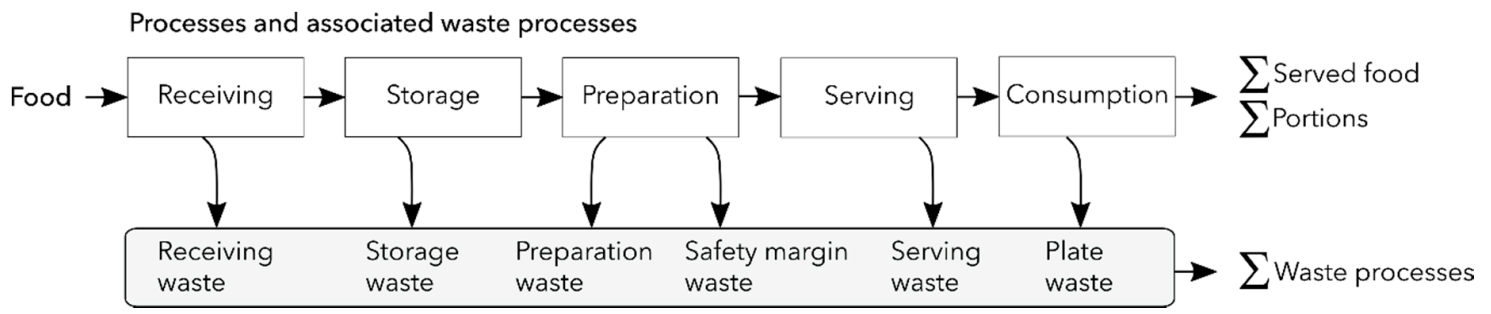

Figure 1. Different waste-generating processes within a kitchen. Food is prepared and wasted during the different steps of work in the kitchen.

\subsection{General Data Collection}

Some of the data used in this study were obtained from organizations that have been quantifying food waste and were willing to share their data, while the remaining data were taken from some previously published studies [14,27,39-41]. All the food-waste quantifications performed by the organizations involved weighing waste masses using various kitchen scales. The results of quantification were documented manually on paper or via spreadsheet software, some kitchens used dedicated food-waste quantification web applications provided by different software companies, and some kitchens used a dedicated smart scale for documentation of the quantification process. Features in common in all cases were that the kitchen staff itself performed the data collection and that the data were sent to a central unit or management within the organization for further compilation and analysis. In a few cases, we helped in the collection of data by sorting out and weighing food waste in the kitchen establishments. Since the organizations that provided data had somewhat different approaches to food-waste quantification, we needed to find common ground between the different set-ups, ambitions, waste process/es monitored, and methods regarding food-waste quantification used by the different organizations. Therefore, all the food-waste quantification data obtained from the organizations were extracted, transformed to a standard format according to Table 3. 
Table 3. Format used for extraction, transformation, and loading of food-waste quantification data from the participating organizations.

\begin{tabular}{lll}
\hline Variable & Definition & Type of Data \\
\hline $\begin{array}{l}\text { Date } \\
\text { Organization }\end{array}$ & $\begin{array}{l}\text { Date of quantification } \\
\text { Kitchen }\end{array}$ & $\begin{array}{l}\text { Date format YYYY-MM-DD } \\
\text { Kitchen where the data came from. }\end{array}$ \\
Type & Name of kitchen or code & Text \\
& Kitchen type & [Production unit, Satellite kitchen] \\
Sector & Segment to which the kitchen belongs & $\begin{array}{l}\text { Hospital, Preschool, Primary } \\
\text { school, Restaurant, Upper }\end{array}$ \\
& & $\begin{array}{l}\text { secondary school] } \\
\text { Meal }\end{array}$ \\
$\begin{array}{l}\text { Waste processes } \\
\text { Waste }\end{array}$ & Type of meal & [Breakfast, Lunch, Dinner, Snack] \\
Served food & Quantified mass from the waste processes & kg \\
Portions & Sum of the mass from all the waste processes & $\mathrm{kg}$ \\
\hline
\end{tabular}

To achieve consistency and transparency, the transformation step included rearranging the quantification data daily per meal and mapping the different waste processes used by the individual kitchens relative to those defined in this study. For instance, when what was defined as "Serving waste" in this study was called something different by a kitchen according to a local standard, the data were transformed and included in the serving waste process [38]. The number of portions recorded for each meal and the amount of food served were compiled and summarized as key performance indicators (KPIs). Since the different organizations used different ways of indicating missing values, all missing values were transformed to a zero value. Figure 2 shows a schematic illustration over the study.

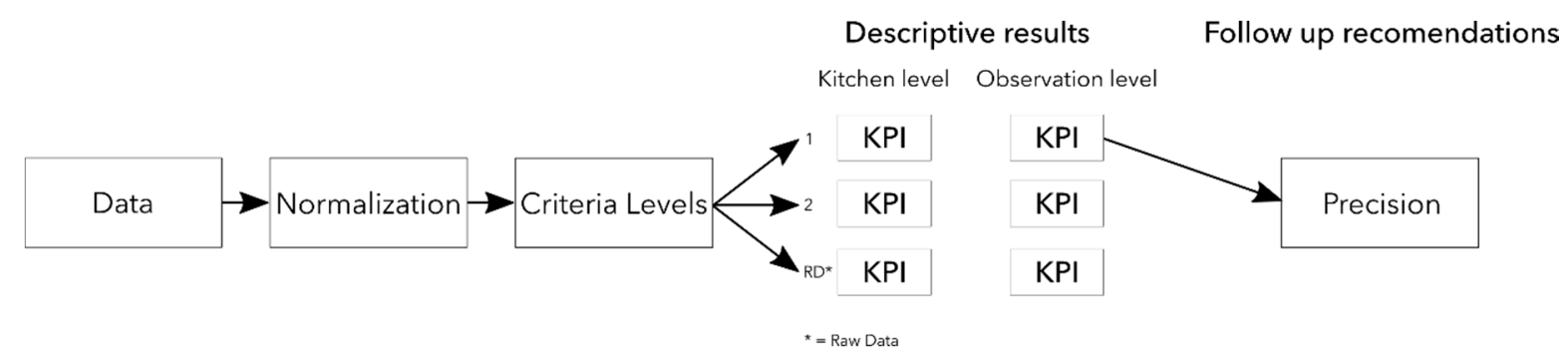

Figure 2. Schematic overview of the study.

\subsection{Cost Sub-Sector of the Hospitality Sector}

This section describes the materials and methods used for the cost sub-sector of the hospitality sector, which includes schools, preschools, elderly care units, and hospitals. Information about food-waste quantification and the data obtained come from establishments in three countries, Sweden, Finland, and Germany. The organizations and companies in the different countries were selected due to willingness to participate and share their data. A total of 760 kitchen establishments from the cost sub-sector were included in the study. Each organization performed waste quantification individually and therefore the quantification periods differed in ambition and in granularity, i.e., number of days the quantification period lasted, number of kitchens participating in quantification, waste processes monitored, and KPIs used for communication. These features also changed over time, e.g., one organization changed the duration of its quantification period from 5 days a year to 15 days a year and included more of its kitchens in quantification work overtime. The earliest food-waste quantification data are from 2010 and the latest from quarter 1 in 2019, but not all organizations actively quantified food waste during the whole period. Despite the different ambitions and granularity in food-waste quantification by the different organizations, most only covered lunch, although preschools 
and especially elderly care establishments typically also serve other meals such as breakfast, snacks, and dinner. Table 4 shows the scope of the material collected for the cost sub-sector of the hospitality sector.

Table 4. Summary of quantified data representing the cost sub-sector of the hospitality sector. All figures rounded to 2-digit precision except for number of quantification days and number of units. The values shown are raw data not subjected to any data cleaning process and may therefore be unrealistic in further calculations.

\begin{tabular}{llllll}
\hline $\begin{array}{l}\text { Actors in the Cost } \\
\text { Sub-Sector }\end{array}$ & $\begin{array}{l}\text { Quantification } \\
\text { Days (n) }\end{array}$ & $\begin{array}{l}\text { Units } \\
(\mathbf{n})\end{array}$ & $\begin{array}{l}\text { Waste } \\
\text { (tons) }\end{array}$ & $\begin{array}{l}\text { Served Food } \\
\text { (tons) }\end{array}$ & $\begin{array}{l}\text { Portions } \\
\left.\mathbf{( 1 0}^{\mathbf{3}}\right)\end{array}$ \\
\hline Elderly care & 2155 & 62 & 110 & 19 & 880 \\
Hospitals & 1018 & 17 & 110 & 9 & 990 \\
Preschool & 6462 & 290 & 32 & 61 & 420 \\
Primary school & 15,183 & 343 & 270 & 740 & 4600 \\
Upper secondary school & 1828 & 48 & 84 & 180 & 1100 \\
Total & 26,646 & 760 & 600 & 1000 & 8000 \\
\hline
\end{tabular}

\subsubsection{Study Material for Elderly Care Units}

Elderly care kitchen units were represented by food-waste quantifications from 20 kitchens in Sweden and 42 in Germany. The total extent of quantification for this segment was 2155 days with waste, served food, or portions quantified.

The definition used for elderly care units in this study was an establishment serving food to people in a retirement home. Some of these establishments are also open to the public, in that relatives can eat in a dining hall with the person living in the establishment.

\subsubsection{Study Material for Hospitals}

Hospitals were represented by food-waste quantifications from 16 hospitals within Sweden and one in Germany. The total number of quantification days was 1018.

Hospitals were defined as large establishments whose purpose is to treat sick people.

\subsubsection{Study Material for Preschools}

Preschool establishments typically care for and educate children ranging from age 1 to 6 years. The food-waste quantification data were obtained from a total number of 290 preschool kitchens, 256 of which were within Swedish municipalities, 15 were in Finland, and 19 were in Germany. Preschools were represented by a total of 6462 quantification days.

\subsubsection{Study Material for Primary Schools}

The material covering the primary school section of this study comprised 296 units from public catering services in Swedish municipalities, 20 units from Finland, and 27 units from Germany. Primary schools were defined as education units where students from around age 6 to 15 participate in education, based on the school system in Sweden and Finland. However, the German school system refers only to the ages 6 to 10 as primary schools.

The number of quantification days for primary schools was a total of 15,183 days. The public catering services for the Swedish municipalities and the Finnish equivalents have a unique position, since the legislation in those countries guarantees pupils and students the right to free meals during school days from pre-primary and primary education until completion of upper secondary education [42-44]. Swedish and Finnish kitchen units typically serve school meals that consist of a warm main course, vegetables, bread, table spread, and a drink [42]. 


\subsubsection{Study Material for Upper Secondary Schools}

Upper secondary school kitchens share some of the characteristics of primary school units, apart from the fact that the guests are older (age 15-19 years in Sweden and Finland, 10-19 in Germany).

The material used in this study comprised 48 such kitchen units, of which 39 were in Sweden, 6 in Finland, and 3 in Germany, with a total of 1828 quantification days.

\subsection{Profit Sub-Sector of the Hospitality Sector}

This section describes the material and methods used for the profit sub-sector of the hospitality sector, which includes canteens, hotels, and restaurants. Information about the food-waste quantifications and the data obtained come from three countries, Finland, Germany, and Norway. These organizations in this case were also selected due to willingness to participate and share their data. A total of 429 kitchen establishments from the profit sector were included in the study. The earliest food-waste quantification data are from 2010 and the latest from quarter 1 in 2019. Table 5 shows the material representing the profit sub-sector of the hospitality sector. In the dataset, it was uncommon for kitchens belonging to the profit sub-sector to quantify the amount of served food.

Table 5. Summary of quantified data representing the profit sub-sector of the hospitality sector. All figures rounded to 2-digit precision except for number of quantification days and number of units. The values shown are raw data not subjected to any data cleaning process and may therefore be unrealistic in further calculations.

\begin{tabular}{cccccc}
\hline $\begin{array}{c}\text { Actors in the Profit } \\
\text { Sub-Sector }\end{array}$ & $\begin{array}{c}\text { Quantification } \\
\text { Days (n) }\end{array}$ & Units (n) & $\begin{array}{c}\text { Waste } \\
\text { (tons) }\end{array}$ & $\begin{array}{c}\text { Served Food } \\
\text { (tons) }\end{array}$ & $\begin{array}{c}\text { Portions } \\
\mathbf{( 1 0}^{\mathbf{3}} \text { ) }\end{array}$ \\
\hline Canteen & 16,130 & 288 & 520 & 4 & 9900 \\
Hotel & 12,583 & 93 & 570 & 0 & 4700 \\
Restaurant & 3453 & 48 & 40 & 2 & 1100 \\
Total & 32,166 & 429 & 1100 & 5 & 15,000 \\
\hline
\end{tabular}

\subsubsection{Study Material for Canteens}

The data for canteens represented 288 units, of which 178 were in Norway, 106 were in Germany, and four were in Finland. Most of the canteens are in company buildings and serve food to the employees, mostly lunch. In some cases, breakfast and dinner are also served. A small number of the canteens also serve food to students in private or public high schools, who by definition fall within the cost sub-sector of the hospitality sector.

\subsubsection{Study Material for Hotels}

The hotel data represented 43 hotels in Germany and 50 hotels in Norway. The dataset represented a diverse range of hotels, ranging from large conference centers to rather small tourist hotels that only serve breakfast. Most of the hotels in Norway recorded food waste over multiple months, thereby covering both the tourism high season in summer and conference activities during the rest of the year.

\subsubsection{Study Material for Restaurants}

The food-waste quantification data representing restaurants included 48 units, of which 39 were in Norway and nine in Finland. The total number of days during which the quantifications were conducted was 3456 . Restaurants are a heterogeneous group, but their defining characteristics are that serving dishes is their primary and only function and they also serve dinner, as opposed to canteens. Most of the restaurants in this study have an à la carte system, where dishes are selected from a menu.

Restaurants that focus mainly on the "takeaway" segment of the market are also included in this group. Some units also offer a buffet lunch during the day. In Finnish restaurants, food-waste 
quantification period lasted for one day and included all the meals the restaurant offered, which were usually lunch and dinner.

\subsection{Food-Waste Quantification and Calculation of KPIs}

This section describes the calculation of various KPIs, techniques for handling asymmetry in the data, and some precision-related topics that can serve as a foundation for tracking food-waste quantification baselines over time.

A harmonized method for developing high-quality baselines is necessary to develop roadmaps for accomplishing the sustainable development goal of reducing food waste by $50 \%$ by 2030 . The first step is to decide which KPIs to trace over time. In this study, we chose to focus on "Waste per portion" and "Waste (\%) of served food". "Waste per portion" was chosen as this indicates how waste is influenced by the number of portions served, but since the portion size varies between different customer groups, it can be argued that food waste in relation to served mass (Waste (\%) of served food) is a better KPI. These indicators are also those used by the organizations that provided the data for internal and external communication. The second step in establishing a sound baseline is ensuring a certain level of data quality. This can be addressed by agreeing within the community which waste processes should be quantified and how this should be done. Typical decisions are whether edible and inedible parts of food should be handled in the quantification work, how long the quantification period should last, how missing data should be handled, and what establishments should take part in the quantification to be representative for the whole segment. Some of these decisions can be taken on a local level, while others need to be addressed on a global level, regarding e.g., how data should be aggregated from local to global level and issues regarding asymmetry and representativeness of the data. However, there is also a need for flexibility, because kitchens locally have different individual problems that they try to solve. For instance, a kitchen might have discovered that it has a problem with serving waste and might therefore only focus on monitoring this form of waste, while neglecting other waste processes. Because of the actions taken on a local level, it is essential to have strict requirements at global level on handling missing and/or skewed data to achieve overall comparability.

\subsubsection{Description and Calculation of "Waste per Portion"}

The data from the organizations were used to calculate the KPI "Waste per portion" for each segment, according to Equation (1), where $i$ represents a daily measurement and $n$ is the total number of quantification days in each segment:

$$
\text { Waste per portion per segment }=\frac{\sum_{i=1}^{n}(\text { Waste from the waste processes })_{i}}{\sum_{i=1}^{n}(\text { Number of portions served })_{i}}
$$

However, the dataset underlying this calculation was not complete, as it contained missing values and did not compensate for the fact that different kitchens monitor different waste processes. For instance, a kitchen could have forgotten to record the number of portions served for some days and or omitted to quantify waste, skewing the result of the calculation. Another challenge to consider is that different kitchens quantify different waste processes, since they focus on identifying different food-waste sources, which causes a problem for the "Waste per portion" indicator on a global level because the underlying data can be inconsistent and can give different results. There is therefore a need for a method that locates missing data points and excles them from the calculation, but also compensates for the fact that kitchens monitor and focus on quantifying different waste processes. As a result, criteria at three levels (Levels 1-3) were used in this study for calculating the "Waste per portion" KPI.

The strictest criterion (Level 1), and that regarded as the most accurate, included only kitchens that had quantified portions and the waste processes "Plate waste" and "Serving waste", since those waste processes have been identified as the most significant contributors of waste in previous food-waste 
quantification studies [14]. When any of these indicators or processes was missing, the quantification for a given day was not included in the assessment.

Based on the medium criterion (Level 2), the calculation needed to include the waste (sum of all waste processes) and portions served, and when one of these two was missing the data were excluded.

The lowest criterion (Level 3) had the same input parameters as Level 2, but with the difference that there was no condition for excluding any missing values for the waste or portion inputs. This can be seen as the raw-data level where data gaps and mistakes are still present.

Descriptive statistics for the Level 1 criterion were calculated according to Equation (2) on kitchen level, using all available quantification data over the years, to examine the results in detail for kitchens belonging to a specific segment of the hospitality sector.

$$
\text { Average waste per portion }=\frac{1}{n} \sum_{i=1}^{n}\left(\sum_{j=1}^{m_{i}} \frac{\text { Waste from the waste processes } i_{i, j}}{\text { Number of portions served } i_{i, j}}\right)
$$

where $n$ represents the number of kitchens in a segment and $m_{i}$ is the number of quantification days for kitchen $i$ in that segment. In addition to producing a table of descriptive statistics, the average waste per portion and the average number of portions on kitchen level were plotted against each other to get a graphical indication of the distribution of the data.

\subsubsection{Description and Calculation of "Waste (\%) of Served Food"}

The KPI "Waste (\%) of served food" was calculated in a similar matter to "Waste per portion" by dividing the calculations into different strict levels by constraining the input parameters for the calculation by various degrees. The reasons for doing this were the same as for calculation of waste per portion and involved compensating for missing input values and for skewness created by the fact that far from all the participating kitchens quantified the amount of served food. The indicator for each segment was calculated based on Equation (3), where $i$ represents aaily measurement and $n$ is the total number of quantification days in each segment:

$$
\text { Waste }(\%)=\frac{\sum_{i=1}^{n}(\text { Waste from waste processes })}{\sum_{i=1}^{n}(\text { Mass of served food })_{i}} \times 100
$$

The strictest criterion (Level 1) for calculating the indicator was to remove any quantification day that lacked information on plate waste, serving waste, or number of guests, with the additional condition that the amount of served food needed to be recorded.

The medium criterion (Level 2) only summed the mass from the waste processes if the amount of served food and number of portions were quantified. It also had the condition to include served food if any waste and portions were quantified for a given day, thus disqualifying all those days for which this information was not present.

The lowest criteria (Level 3) added all the mass from the waste processes and divided it by the mass of served food with no condition at all. This can be seens the raw-data level where data gaps and mistakes were still present.

Descriptive statistics for Level 1 were calculated on kitchen level to examine the results in detail, based on the Equation (4):

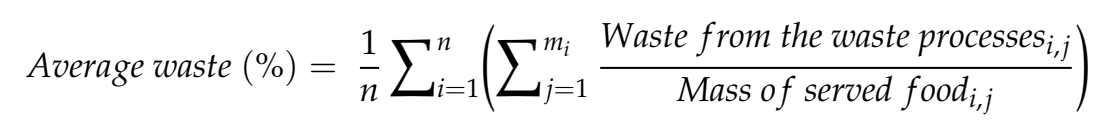

where $n$ represents the number of kitchens in a segment and $m_{i}$ is the number of quantification days from kitchen $i$ in that segment. 


\subsubsection{Evaluation of the KPIs}

To understand how the KPI changed with the results from computations using the different criteria levels the results were arranged in tables, one for "Waste per portion" and one for "Waste (\%) of served food".

\subsubsection{Distribution of the Waste Processes per Sector}

To get an understanding of how the waste quantifications for the different segments were distributed and to identify where the main waste occurs, the "Waste per portion" indicator obtained with the strictest criterion (Level 1) was used.

$\mathrm{T}$ results from each waste process were displayed as a stacked bar plot to reveal the dominant waste processes in each segment of the sectors.

\subsubsection{Precision of the Key Performance Indicator "Waste per Portion"}

To compare KPIs, it is necessary to determine the measurement precision of the indicator over time. Since it is relatively easy to quantify waste and the number of portions compared with quantifying the amount of served food [26,39], the question is how many quantification days are needed to ensure a certain level of precision for "Waste per portion". The first step in this was to determine the distribution of the data for the strictest criterion. The data analyzed in this study were highly skewed for the different segments (Figure 3), but according to the central limit theorem, the average can be approximated as a normal distribution if the sample size is sufficiently large [45].
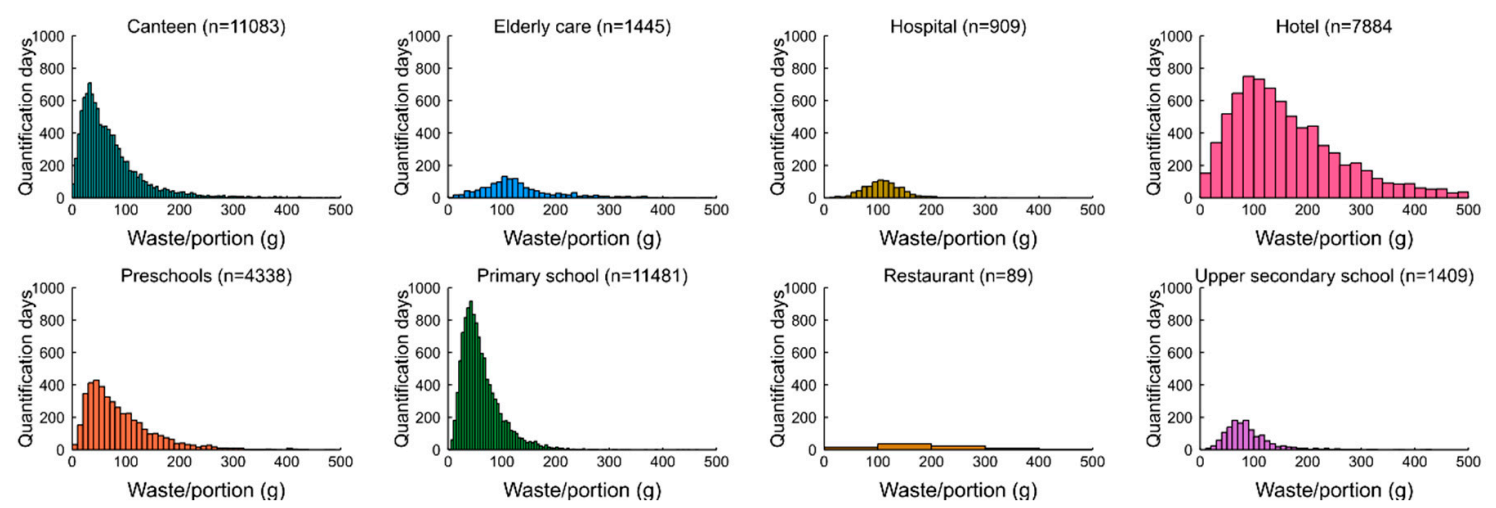

Figure 3. Histograms showing "Waste per portion" according to the strictest criterion for kitchens within the hospitality sector of the organizations studied: canteens $(\bullet)$, elderly care $(\bullet)$, hospitals $(\bullet)$, hotels $(\bullet)$, preschools $(\bullet)$, primary schools $(\bullet)$, restaurants $(\bullet)$, and upper secondary schools $(\bullet)$. X-axis capped at $500 \mathrm{~g} /$ portion.

This makes it possible to calculate the confidence interval $\mathrm{I}_{\mu}$ (Equation (5)) and the length of the confidence interval (Equation (6)), which in this case is the precision in quantification of "Waste per portion". To find out how this changes with the number of observation points, in our case quantification days, equation 4 can be solved for $n$ to give the number of observation points needed to get a certain quantification precision in grams (Equation (7)):

$$
\begin{gathered}
I_{\mu}=\left(\overline{\mathrm{x}} \pm t_{\alpha}\left(\frac{\sigma}{\sqrt{n}}\right)\right) \\
L=2 t_{\alpha} \frac{\sigma}{\sqrt{n}} \\
n=4\left(t_{\alpha} \frac{\sigma}{L}\right)^{2}
\end{gathered}
$$


where $I_{\mu}$ is confidence interval, $\bar{x}$ is sample mean, $t_{\alpha}$ is confidence level for different $\alpha, \sigma$ is standard deviation, $\mathrm{n}$ is observation point, and $\mathrm{L}$ is interval length given by Equation (6).

Both the observations $n$ (5) and interval length $L(4)$ are plotted against each other, to provide an illustration of how the measurement precision changes with the number of observation points per segment studied. In this study, a 95\% confidence interval of $\alpha=0.025$ was used according to the $\mathrm{t}$-distribution. This approach gives information about the precision regarding the average "Waste per portion" for the strictest criterion.

\subsubsection{Waste per Portion over Time}

To get a sense of the change over time in the "Waste per portion" indicator for the strictest criterion, the precision attached to this indicator was plotted as grouped bar plots per segment together with the precision information for the different years and the number of quantification days per year.

\section{Results}

The results showed that around $20 \%$ of all food served was wasted within the hospitality sector organizations studied (Table 6), based on the strictest criterion (Level 1) for all years for which data were available.

Table 6. Waste (\%) of served food in the different segments of the hospitality sector according to the strictest criterion (Level 1), aggregated on kitchen level for all years for which data were available.

\begin{tabular}{|c|c|c|c|c|c|c|c|c|c|}
\hline Sector & $\begin{array}{l}\text { Kitchens } \\
\text { (n) }\end{array}$ & $\begin{array}{c}\text { Min } \\
(\%)\end{array}$ & $\begin{array}{c}\text { Max } \\
(\%)\end{array}$ & $\begin{array}{c}1^{\text {st }} \text { Quartile } \\
(\%)\end{array}$ & $\begin{array}{c}\text { Median } \\
(\%)\end{array}$ & $\begin{array}{c}3^{\text {rd }} \text { Quartile } \\
(\%)\end{array}$ & $\begin{array}{c}\text { Mean } \\
(\%)\end{array}$ & $\begin{array}{l}\text { Std. Dev. } \\
(\%)\end{array}$ & $\begin{array}{c}\text { Waste } \\
(\%)\end{array}$ \\
\hline Canteen & 5 & 22.5 & 35.8 & 24.6 & 28.6 & 33.0 & 28.9 & 5.0 & 26.3 \\
\hline Elderly care & 8 & 15.9 & 62.2 & 18.4 & 23.3 & 25.1 & 26.4 & 14.0 & 20.6 \\
\hline Hospital & - & - & - & - & - & - & - & - & - \\
\hline Hotel & - & - & - & - & - & - & - & - & - \\
\hline Preschool & 148 & 6.7 & 111 & 16.5 & 23.8 & 32.1 & 25.9 & 13.0 & 22.3 \\
\hline Upper secondary school & 35 & 8.2 & 39.1 & 15.7 & 19.5 & 23.0 & 20.0 & 6.1 & 17.8 \\
\hline Total & 431 & 6.7 & 111 & 15.5 & 20.2 & 25.6 & 21.9 & 9.8 & 20.0 \\
\hline
\end{tabular}

The data underlying the calculations in Table 6 comprised 9061 quantification days. Upper secondary schools showed the lowest "Waste (\%) of served food" (17.8\%). However, only 35 upper secondary schools provided data for this calculation, as a result of the strict criterion disqualifying schools with incomplete and or lacking data. Primary school kitchens had the second lowest value of served food wasted $(19.7 \%)$ and provided most data in terms of number of kitchens. The value for elderly care was $20.6 \%$ of served food, while preschools reported that $22.3 \%$ of served food was wasted. Canteens and restaurants reported higher waste levels, $26.3 \%$ and $24.3 \%$ of served food, respectively. Hospitals and hotels gave no indication for the strictest criterion, since none met the requirements for Level 1.

The other KPI studied, "Waste per portion", gave a more varied picture, with an average of 50 to $192 \mathrm{~g}$ per portion wasted within the hospitality sector (Table 7) according to the strictest criterion. 
Table 7. Waste per portion (g) in the different segments of the hospitality sector according to the strictest criterion (Level 1), aggregated on kitchen level for all years for which data were available.

\begin{tabular}{|c|c|c|c|c|c|c|c|c|c|}
\hline Sector & $\begin{array}{l}\text { Kitchens } \\
\text { (n) }\end{array}$ & Min (g) & $\operatorname{Max}(g)$ & $\begin{array}{c}1^{\text {st }} \text { Quartile } \\
\text { (g) }\end{array}$ & $\begin{array}{l}\text { Median } \\
\text { (g) }\end{array}$ & $\begin{array}{c}3^{\text {rd }} \text { Quartile } \\
\text { (g) }\end{array}$ & $\begin{array}{l}\text { Mean } \\
\text { (g) }\end{array}$ & $\begin{array}{c}\text { Std. } \\
\text { Dev. (g) }\end{array}$ & $\begin{array}{c}\text { Waste/Portion } \\
\text { (g) }\end{array}$ \\
\hline Canteen & 230 & 2.70 & 440 & 36.0 & 62.0 & 103 & 83.5 & 73.9 & 50.1 \\
\hline Elderly care & 49 & 22.2 & 790 & 94.1 & 122 & 157 & 154 & 122 & 129 \\
\hline Hotel & 83 & 5.50 & 405 & 83.7 & 125 & 195 & 144 & 81.7 & 141 \\
\hline Preschool & 193 & 20.8 & 399 & 53.2 & 87.0 & 116 & 94.6 & 56.2 & 81.0 \\
\hline Primary school & 322 & 15.2 & 244 & 47.0 & 60.2 & 78.5 & 65.5 & 28.8 & 59.0 \\
\hline $\begin{array}{l}\text { Upper secondary } \\
\text { school }\end{array}$ & 46 & 40.8 & 181 & 63.0 & 81.5 & 104 & 88.8 & 33.5 & 78.9 \\
\hline Total & 954 & 2.70 & 790 & 48.9 & 72.6 & 108 & 91.4 & 69.1 & 75.3 \\
\hline
\end{tabular}

Canteens had the lowest waste per portion $(50.1 \mathrm{~g})$ and were also the second largest segment in terms of recorded data, with 11,083 quantifications days for the 230 units that delivered data meeting the strictest criterion. Hotels had the second highest value for waste per portion $(141 \mathrm{~g})$, based on 83 kitchens and 7884 quantification days. Elderly care reported slightly lower waste per portion (129 g), based on 49 kitchens and 1445 quantification days. Hospitals reported $113 \mathrm{~g}$ waste per portion, with data from 16 kitchens and a total of 909 quantification days. Preschools and upper secondary school units reported similar waste per portion $(81 \mathrm{~g}$ and $78.9 \mathrm{~g}$, respectively). Primary schools had the second lowest waste per portion $(59 \mathrm{~g})$ and had the largest number of kitchens providing data for the calculations, with 322 kitchens and 11,481 quantification days in total. Restaurants was the segment with most waste per portion (192 g), based on data from 15 kitchens and 89 quantification days. The total number of quantification days, independent of segment studied, was 38,638 days (from 954 kitchen units) according to the strictest criterion.

Comparing the results for "Waste per portion", aggregated on kitchen level for all available data according to the strictest criterion (Table 7) against the average number of reported portions (Figure 4), revealed that preschools as a segment typically serve fewer portions than e.g., upper secondary schools, but displayed quite a broad range of "Waste per portion". Upper secondary schools, on the other hand, serve rather many portions but were quite consistent in their "Waste per portion" levels. Primary schools occupied an intermediate position, with 490 recorded portions and 60-70 g per portion, and showed a similar pattern as upper secondary schools, but with somewhat lower "Waste per portion" levels and a broader spectrum of recorded portions. Elderly care units rarely go under $100 \mathrm{~g}$ per portion, with some exceptions, and serve quite a broad range of portions on average. Hospitals show the same characteristics as upper secondary schools, but with a higher number of recorded portions. Canteens display quite a broad range in terms of both number of recorded portions and average waste per portion, while hotels have slightly higher average waste per portion. Restaurants are quite few, but centered on 200 portions and quite high waste levels, ranging between 100 to $200 \mathrm{~g}$ per portion. 


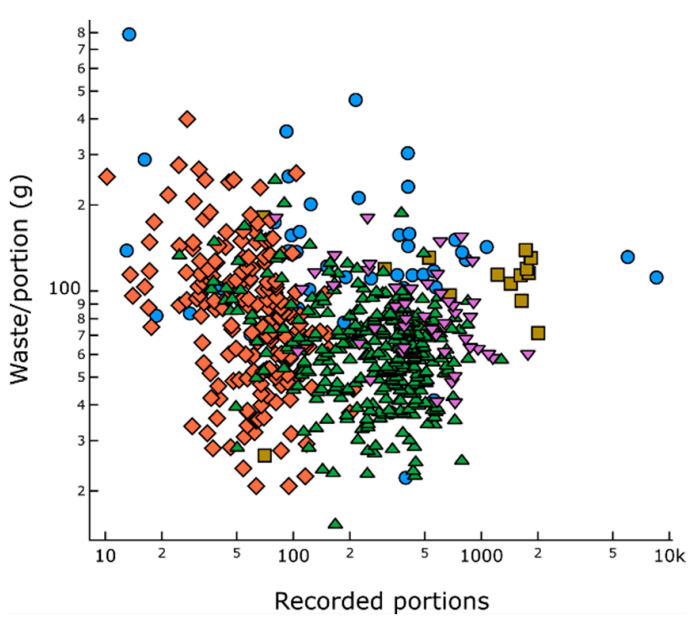

(a) Cost sub-sector

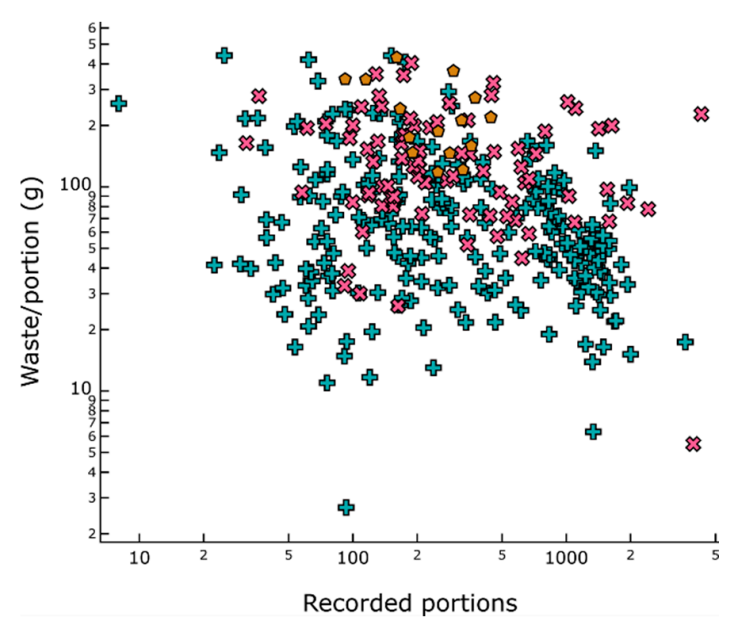

(b) Profit sub-sector

Figure 4. Scatterplots of average waste per portion and average number of portions served according to the strictest criterion (Level 1) for the kitchens of the organizations studied within (a) elderly care ( $O$ ), hospitals $(\square)$, preschools $(\diamond)$, schools $(\Delta)$, and upper secondary schools $(\nabla)$ in the cost sub-sector and (b) canteens (§), hotels ( $($ ) and restaurants $(\Delta)$ in the profit sub-sector. Axis by logarithmic scale.

\subsection{Distribution of Waste}

Comparing the waste distribution among the different segments of the sectors and waste processes, "Plate waste" appeared to be the dominant type of waste in canteens, elderly care, hotels, and upper secondary schools and almost equal to "Serving waste" in the hospital segment (Figure 5). "Serving waste" was the major contributor to the waste processes for preschools, primary schools, and hotels. "Preparation waste" was the largest contributor to restaurant waste. "Storage waste" was quite a small proportion of waste in the different segments and there were no records of "Receiving waste" at the strictest criterion for any of the segments studied.

\section{Waste/portion (g) per segment according to strictest criteria level}

Upper secondary school

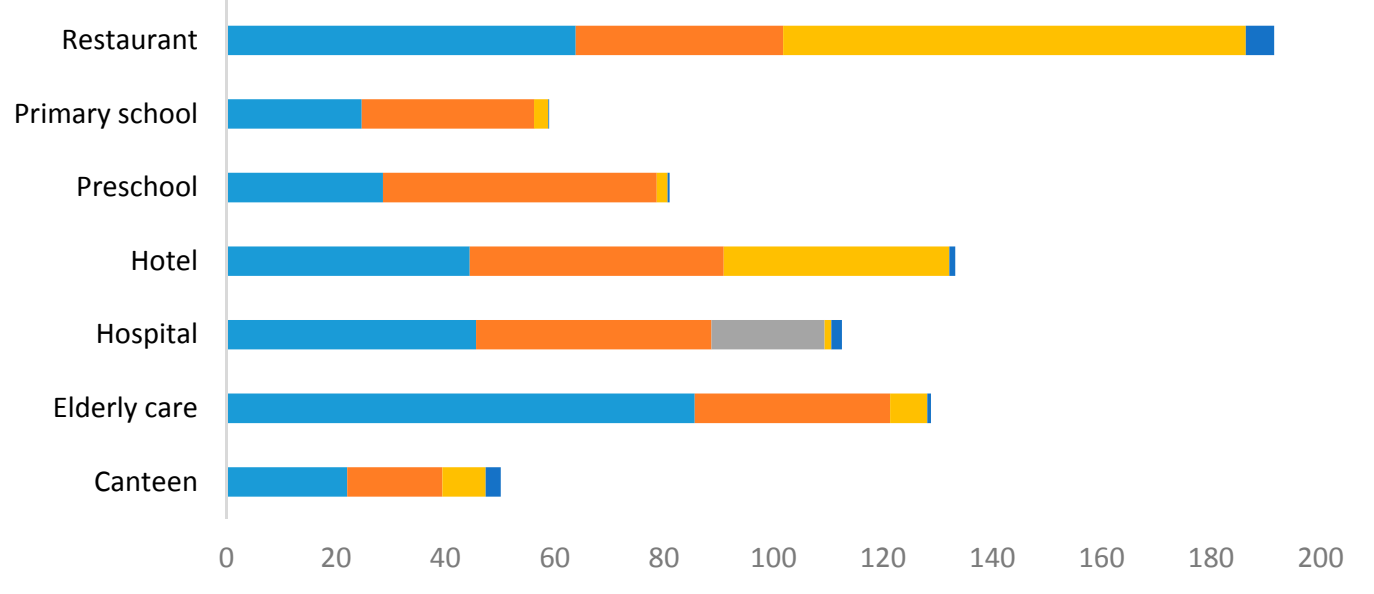

Figure 5. Contribution of different waste generation processes to total waste according to the strictest

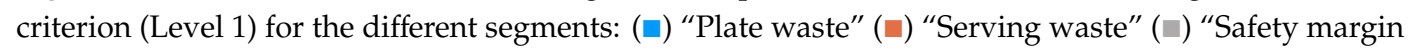

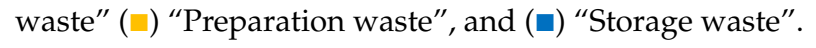




\subsection{Precision of the KPIs}

Figure 6 shows how the measurement precision of the KPI "Waste per portion" changes with the number of quantification days. Based on the strictest criterion, hospitals with 909 eligible quantification days achieved precision of $\pm 2.7 \mathrm{~g}$. Primary schools, with 11,481 quantification days, achieved precision of $\pm 0.8 \mathrm{~g}$. Preschools, which according to Level 1 reported 4388 quantification days, achieved precision of $\pm 3.2 \mathrm{~g}$. Elderly care ( 1445 quantification days) achieved precision of $\pm 5.8 \mathrm{~g}$ and upper secondary schools (1409 quantification days) precision of $\pm 12 \mathrm{~g}$. Restaurants ( 89 quantification days according to the strictest criterion) achieved precision of $\pm 31 \mathrm{~g}$, hotels (7884 observation points) precision of $\pm 6.4 \mathrm{~g}$, and canteens $(11,083)$ quantification days precision of $\pm 9.4 \mathrm{~g}$.

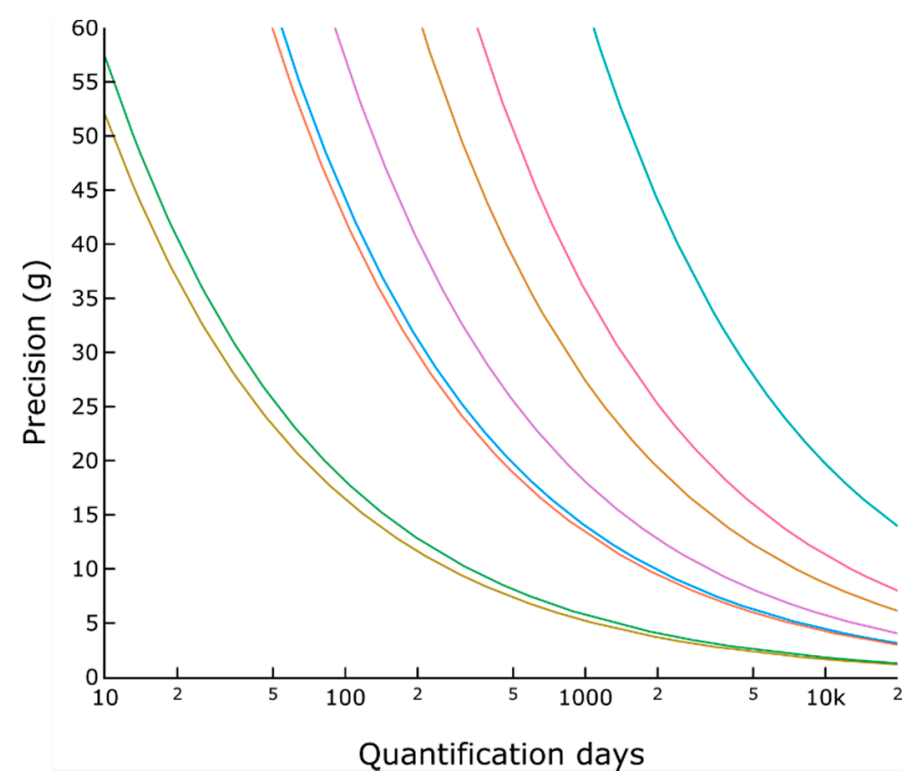

Figure 6. Measurement precision in the key performance indicator "Waste per portion" and number of quantification days for hospitals (-), primary schools (-), preschools (-), elderly care (-), upper secondary schools $(-)$, restaurants $(-)$, hotels $(-)$, and canteens $(-)$.

The differences between the criteria levels are shown in Tables 8 and 9. These differences show that the KPIs "Waste (\%) of served food" and "Waste per portion" can vary depending on the input used.

When data were available for computation of "Waste (\%) of served food", the results for the strictest and medium criteria (Levels 1 and 2) did not vary greatly within segments (Table 8). However, the lowest criterion gave no reliable results for the segments canteens, elderly care, hospitals, and restaurants. For instance, for the canteen segment, the calculation based on Level 3 resulted in a value of $11,839 \%$ for "Waste (\%) of served food", because very few canteens quantified the amount of served food and the waste part dominated the calculation, producing unreliable results. A similar tendency was observed with the Level 3 criterion for upper secondary schools, with a 28 percentage-point difference between Levels 2 and 3 . 
Table 8. "Waste (\%) of served food" in the different sectors for the criteria levels and number of quantification days that the levels include. Digits rounded for the columns "Recorded waste" and "Served food". "-" indicates that no data were available for the calculation, "NR" that results were not reasonable.

\begin{tabular}{|c|c|c|c|c|}
\hline Sector & $\begin{array}{l}\text { Quantification } \\
\text { Days (n) }\end{array}$ & $\begin{array}{l}\text { Recorded Waste } \\
\text { (tons) }\end{array}$ & Served Food (tons) & Waste $(\%)$ \\
\hline \multicolumn{5}{|l|}{ Canteen } \\
\hline Level 1: Strictest & 41 & 1 & 3.8 & 26 \\
\hline Level 2: Medium & 43 & 1.1 & 4.4 & 25 \\
\hline $\begin{array}{l}\text { Level 3: Lowest } \\
\text { Elderly care }\end{array}$ & NR & NR & NR & NR \\
\hline Level 1: Strictest & 288 & 1.9 & 9.2 & 21 \\
\hline Level 2: Medium & 442 & 3.3 & 16 & 21 \\
\hline $\begin{array}{l}\text { Level 3: Lowest } \\
\text { Hospital }\end{array}$ & NR & NR & NR & NR \\
\hline Level 1: Strictest & - & - & - & - \\
\hline Level 2: Medium & 83 & 2.4 & 9.5 & 25 \\
\hline Level 3: Lowest & NR & NR & NR & NR \\
\hline Hotel & - & - & - & - \\
\hline \multicolumn{5}{|l|}{ Preschool } \\
\hline Level 1: Strictest & 2512 & 11 & 50 & 22 \\
\hline Level 2: Medium & 2788 & 12 & 55 & 22 \\
\hline Level 3: Lowest & 3105 & 32 & 61 & 52 \\
\hline \multicolumn{5}{|l|}{ Primary school } \\
\hline Level 1: Strictest & 5573 & 120 & 600 & 20 \\
\hline Level 2: Medium & 5922 & 120 & 630 & 19 \\
\hline $\begin{array}{l}\text { Level 3: Lowest } \\
\text { Restaurant }\end{array}$ & 6739 & 270 & 740 & 36 \\
\hline Level 1: Strictest & 9 & 0.6 & 2.4 & 25 \\
\hline Level 2: Medium & 9 & 0.6 & 2.4 & 25 \\
\hline Level 3: Lowest & NR & NR & NR & NR \\
\hline \multicolumn{5}{|c|}{ Upper secondary school } \\
\hline Level 1: Strictest & 638 & 29 & 160 & 18 \\
\hline Level 2: Medium & 689 & 30 & 170 & 18 \\
\hline Level 3: Lowest & 757 & 84 & 180 & 46 \\
\hline
\end{tabular}

Table 9 provides a similar picture for "Waste per portion" as shown in Table 8 for "Waste (\%) of served food". The most significant difference was that waste per portion remained quite consistent over the different criteria levels and did not fluctuate as drastically as the "Waste (\%) of served food" indicator. The most significant difference between the Level 1 and Level 3 criteria was found for restaurants, which according to Level 1 reported waste of $192 \mathrm{~g} /$ portion with 89 quantification days and according to Level 3 waste of $58.5 \mathrm{~g} /$ portion with 3453 quantification days. 
Table 9. "Waste per portion (g)" in the different sectors for the criteria levels and number of quantification days that the levels include. Digits rounded for the columns "Recorded waste" and "Recorded portions".

\begin{tabular}{|c|c|c|c|c|}
\hline Sector & $\begin{array}{l}\text { Quantification } \\
\text { Days (n) }\end{array}$ & $\begin{array}{l}\text { Recorded Waste } \\
\text { (tons) }\end{array}$ & $\begin{array}{l}\text { Recorded Portions } \\
\qquad\left(10^{3}\right)\end{array}$ & $\begin{array}{c}\text { Waste/Portion } \\
\text { (g) }\end{array}$ \\
\hline \multicolumn{5}{|l|}{ Canteen } \\
\hline Level 1: Strictest & 11,083 & 420 & 8400 & 50.1 \\
\hline Level 2: Medium & 15,290 & 510 & 9900 & 51.7 \\
\hline $\begin{array}{l}\text { Level 3: Lowest } \\
\text { Elderly care }\end{array}$ & \multicolumn{3}{|c|}{ Elderly care } & 52.8 \\
\hline Level 1: Strictest & 1445 & 100 & 780 & 128 \\
\hline Level 2: Medium & 2065 & 110 & 880 & 123 \\
\hline Level 3: Lowest & 2155 & 110 & 990 & 124 \\
\hline \multicolumn{5}{|l|}{ Hospital } \\
\hline Level 1: Strictest & 909 & 110 & 940 & 112 \\
\hline Level 2: Medium & 1017 & 110 & 990 & 112 \\
\hline Level 3: Lowest & 1018 & 110 & 990 & 112 \\
\hline \multicolumn{5}{|l|}{ Hotel } \\
\hline Level 1: Strictest & 7884 & 400 & 2900 & 141 \\
\hline Level 2: Medium & 12,308 & 570 & 4600 & 122 \\
\hline Level 3: Lowest & 12,583 & 570 & 4700 & 122 \\
\hline \multicolumn{5}{|l|}{ Preschool } \\
\hline Level 1: Strictest & 4338 & 24 & 300 & 80.1 \\
\hline Level 2: Medium & 5589 & 30 & 400 & 74.4 \\
\hline Level 3: Lowest & 6462 & 30 & 420 & 74.7 \\
\hline \multicolumn{5}{|l|}{ Primary school } \\
\hline Level 1: Strictest & 11,083 & 220 & 3800 & 59.0 \\
\hline Level 2: Medium & 14,089 & 250 & 4600 & 53.7 \\
\hline Level 3: Lowest & 15,183 & 270 & 4600 & 57.8 \\
\hline \multicolumn{5}{|l|}{ Restaurant } \\
\hline Level 1: Strictest & 89 & 4.2 & 22 & 192 \\
\hline Level 2: Medium & 2092 & 38 & 500 & 75.9 \\
\hline Level 3: Lowest & 3453 & 41 & 700 & 58.5 \\
\hline \multicolumn{5}{|l|}{ Upper secondary school } \\
\hline Level 1: Strictest & 1409 & 71 & 910 & 78.9 \\
\hline Level 2: Medium & 1737 & 82 & 1100 & 72.1 \\
\hline Level 3: Lowest & 1828 & 84 & 1100 & 73.7 \\
\hline
\end{tabular}

\subsection{Waste per Portion over Time}

Figure 7 shows how the different segments of the hospitality sector performed according to the strictest criterion for "Waste per portion" over time when examining the data from a quantification day perspective. Primary schools were the only segment to show a decreasing trend that in the later years did not overlap in terms of quantification precision (error bars in Figure 7), except for the first quarter of 2019. Other segments showing decreasing waste per portion were upper secondary schools and hospitals, but those segments gave highly imprecise results due to overlap of error bars. The same is true for preschools, which appeared to have increasing levels of waste per portion, but again the error bars overlap, making this finding very imprecise. Elderly care was quite stationary, but for the first quarter of 2019 the calculated value appeared to increase relative to that in previous quantification periods. 


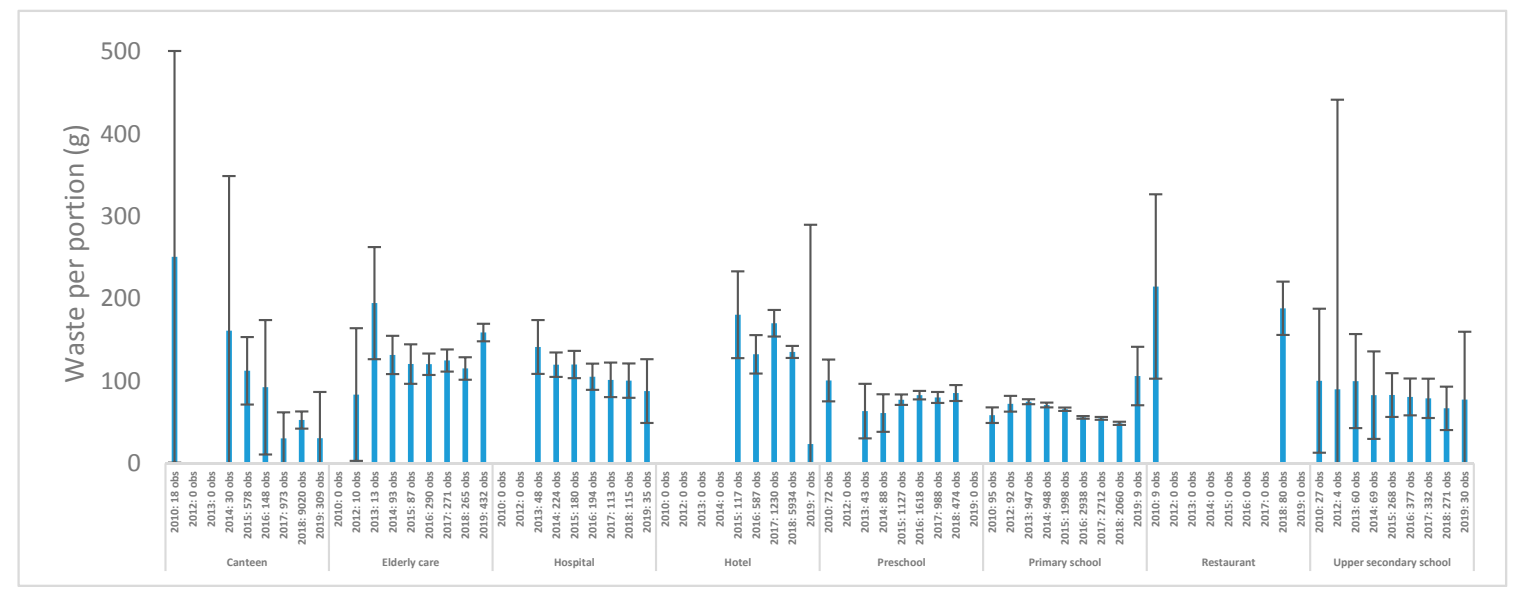

Figure 7. "Waste per portion (g)" with measurement precision (error bars) for the segments over time according to the strictest criterion (Level 1).

Restaurants could only provide results for 2010 and 2018 according to the strictest criterion. Hotels provided quite erratic results, but with 2018 showing a decrease compared with 2017. However, the error bars for 2016 overlapped both the 2017 and 2018 results. Canteens decreased their initial "Waste per portion" value the most, but again error bar overlap makes the result imprecise.

\section{Discussion}

\subsection{Food Waste within the Different Segments of the Hospitality Sector}

The dataset underlying this study is larger than in previous studies $[14,20,22,23,25,27,28,30,32,34]$ and provides some perspective for previous findings. Among the organizations providing data for this study, it is quite normal to report around $20-26 \%$ waste, irrespective of the segment within the hospitality sector. However, this is higher than values reported by Betz [32] (10.7\% and 7.7\% waste for two kitchens investigated). The reason for those low values may that Betz quantified mass of delivered food, and not mass of served food as in the present study. However, the waste levels at the organizations contributing to this study are slightly lower than the $27 \%$ and $27.5 \%$ reported by Martins [25] and Boschini [26] according to the strictest criterion in this study. However, the variations in the results we observed when comparing criteria levels for "Waste (\%) of served food" and when comparing the different segments indicate that the results from all previous studies can be regarded as falling within the "normal" range.

The KPI "Waste per portion" can vary widely between segments within the hospitality sector, ranging from around $50 \mathrm{~g}$ per portion for canteens up to around $192 \mathrm{~g}$ per portion for restaurants. These values are approximately in line with previous findings for the same segments of the hospitality sector, disregarding criteria levels and how much material to include when calculating this KPI.

The level of "Waste per portion" found for preschools in this study was intermediate relative to previous findings. In the study by Eriksson [14], preschools reported that around $45 \mathrm{~g}$ per portion served was wasted, which is lower than the value found in this study $(\sim 81 \mathrm{~g})$. However, Byker [20] and Hansson [33] reported levels of $210 \mathrm{~g}$ and $145 \mathrm{~g}$, respectively, which is in the upper end of our "Waste per portion" range. Use of more observation points would probably make the KPIs benchmarked here converge to an average in values in previous studies. Preschools have the potential to control food waste better than e.g., upper secondary school units, which for all years covered by the data reported a waste value of $78.9 \mathrm{~g} /$ portion, i.e., similar to that obtained for preschools. At first glance, the diagram showing "Waste per portion" in the different segments together with the error bars for the different years gives the impression that overall, preschools are increasing their waste per portion and upper secondary schools are decreasing theirs. However, the error bars for both segments overlap, creating uncertainty about whether the segments have made any progress. 
The measurement error for the different years arises because the segments provided different numbers of quantification days for calculation of the indicator. For instance, preschools had 474 quantification days for 2018, resulting in precision of roughly $\pm 10 \mathrm{~g}$, and upper secondary schools had 271 quantification days and precision of around $\pm 26 \mathrm{~g}$, which resulted in an overlap and put the segments on a similar level. Looking at the precision in all the available data, it was around $\pm 11 \mathrm{~g}$ for upper secondary schools and $\pm 3 \mathrm{~g}$ for preschools, because the distribution of the data differed for these segments.

Considering the quite high values of "Waste per portion" for preschools and the seemingly increasing trend, there is considerable potential to reduce waste in this segment, especially since preschool units have lower levels of the risk factors involved in food-waste generation. For example, the carers eat with the guests and can therefore monitor and encourage the guests to minimize food waste. The guests in preschool units also usually have fewer options to choose from and cannot choose to eat elsewhere which, according to previous studies, should have a reducing effect on food waste $[46,47]$.

The distribution of waste in the different segments of the hospitality sector was similar to that found in previous studies [14], which is interesting since it indicates that this parameter is unaffected by the amount of data collected. This provides a good opportunity for improvement, since kitchens with different set-ups and organizational characteristics can learn from other successful kitchens. For instance, measures that work to reduce plate waste in one kitchen establishment should at least be tried by others and evaluated.

\subsection{Uncertainties and Limitations}

This study did not include all sectors within the hospitality sector and omitted data from prisons and other such establishments in the public sector. To get a complete picture, these and other small actors in the profit sub-sector should be included in the analysis.

Organizations collected the data on which this study was based on their own and no random sampling was made among participating organizations. However, since food-waste quantification is not compulsory in the study countries, it was not possible to conduct a random selection of all units, only volunteering units. The data are more likely to have originated from organizations that are interested and have some ambition to lower their waste levels, so is highly likely that the results in this study are biased and that the actual waste levels are higher. Therefore, it cannot be claimed that the results presented are representative for whole segments.

The organizations conducted data collection in slightly different ways, which is clearly a limitation for this study since it introduces another bias. However, there will always be variation and error due to the human factor in any self-reporting system, and the risk is to some extent reduced using a larger dataset. Another limitation regarding data collection is the possible inclusion of napkins (and possibly other waste) in the plate waste fraction from some units and whether inedible parts were included or excluded. Lastly, there could be a significant variation in how liquid foods (soups, sauces, stews, etc.) are treated, since various amounts of the liquid phase could be included in food-waste quantification.

In this study, we tried to overcome some of the limitations by introducing different criteria levels. Level 1, the strictest, reflected the actual levels of waste, since quantifications based only on some waste processes and or served amount of food or with missing values were excluded. Applying this criterion also to some extent compensated for the highly skewed data, making calculations for the baselines fairer than they would otherwise have been. However, this is not a guarantee that the data included in the strictest criterion are correct, since they can be obtained in several ways. For instance, the number of portions might be incorrect, a kitchen might have forgotten to quantify a waste-generating process (which would not disqualify it under the strictest level), or the in-data could have been compromised by reporting of false information. A common mistake found during the conversion process was kitchens expressing values in grams and not kilograms. This was handled before the data were used for the calculations in this study, but it is an example of how data can be compromised in one way or another. 
The different KPIs chosen in this study yielded quite different results, since one described the number of portions, which can vary widely between the segments in the hospitality sector, and the other the amount of served food that was wasted. It is necessary to have at least two indicators as input to a future baseline to give a complete picture of the situation. The different results reflect differences in quantification ambitions, where some organizations have been keener to quantify the amount of served food. One should also bear in mind that quantification of the amount of served food is a cumbersome task and the results can show great variation depending on the thoroughness of the individual kitchen staff. The best way to get precise information in food-waste quantifications would be for kitchens in all organizations to quantify waste all the time and to share their findings. Since this is an unlikely scenario, there is a need for recommendations to organizations already involved and interested in the matter.

\subsection{The Road to 2030}

Some national initiatives $[48,49]$ have put forward quantification standards. This is an essential first step to increase the number of participating organizations and to make the quantification data comparable and representative among participating organizations. Having more quantification data would increase knowledge and allow the findings to be put into context and to be traceable over time. To halve food waste in the hospitality sector, it is essential that the KPIs that make up different future baselines have sufficient precision and resolution to be comparable over time. As an example, primary schools currently have a waste level of around $59 \mathrm{~g}$ per portion served based on the data for all years included under the strictest criterion in this study. To reach the goal of halving food waste, by 2030 primary schools would achieve a waste level of $\sim 30$ g per portion served, which is roughly a $3 \mathrm{~g}$ per year decrease $( \pm 1.5 \mathrm{~g})$, to achieve SDG 12.3. To track development over time, the precision in quantification would need to be less than $3 \mathrm{~g}$ for the "Waste per portion $(\mathrm{g})$ " key performance indicator if quantifications were performed every year. To achieve that precision, more data would need to be collected. The restaurant segment is an excellent example of this, with only 89 quantification days providing data for the precision calculation according to the strictest criterion. It is doubtful whether this can be seen as a sufficiently large number of observation points to perform the precision analysis.

To achieve the goal of halving food waste by 2030 , it is essential that the baselines provided by different initiatives have sufficient precision and representativeness, to create trust in the values. The first step in achieving this is to establish the purpose of the baselines, when they are supposed to be followed up, and how. In that work, it is also essential to address the nature of the food waste, as there is currently limited information on the amount of e.g., edible food waste being generated. A general recommendation is that organizations participating in quantification should use the same method or framework, to make the underlying data for the baselines transparent. However, one must be pragmatic and meet organizations where they are [39], and minimum requirements for participating in delivering data to baseline quantifications should be smooth and not a reporting burden on the kitchen staff. One way of doing this is to use digitalization as a tool, which would hopefully enable instant feedback to the kitchen instead of delayed reports that make it impossible for kitchens to understand the effects of different measures. The levels of the waste process monitored should also be tailored to the kitchen's needs, while still fitting within a standard framework $[38,39]$. Recommendations for future work are thus to devise conventional means and methods of quantification and meet organizations where they are, but still have pressure to push development forward and e.g., include served food as a requirement for quantifications, in order to get a clearer picture of the KPI "Waste (\%) of served food". National standards and frameworks are one way of doing this, but it is important to consider what the baselines are trying to achieve and to be clear about this in advance, to set criteria that enable the precision needed for follow-up. More quantification efforts are needed at canteens, elderly care establishments, hospitals, hotels, preschools, restaurants, and upper secondary schools, which will require greater precision of performance as they reduce their waste to show whether they are on 
target or not. Tools and measures for minimizing the actual causes of food waste and unnecessary overproduction $[40,41]$ are also urgently needed, so that the things that get measured can be managed.

\section{Conclusions}

Overall, $50-192 \mathrm{~g}$ per portion or around $20 \%$ of served food are wasted. However, precision is crucial when monitoring different KPIs over time to detect trends. A decreasing trend, such as that observed here for hospitals, might emerge when comparing the average results from year to year, but the precision of quantification (measurement error) gives additional information about the trend. Hospitals are also a good example of a segment that provides quite similar quantification results over time, e.g., for "Waste per portion", and therefore fewer quantification days can provide quite accurate calculation of this KPI. Other segments have problems with this because they may have a lot of waste on some days, which influences the precision of "Waste per portion".

Depending on how the indicators are evaluated, somewhat different results can be obtained. Here, there were marked differences between the highest and lowest criteria (Levels 1 and 3) set for "Waste $(\%)$ of served food". In some segments, few kitchens quantify the amount of served food, making this KPI impractical to study. The indicator "Waste (\%) of served food" is also more difficult to quantify and requires the different segments to quantify amount of served food. Applying the Level 2 criterion for analysis might be a reasonable compromise, since it would allow more quantification days as input for the precision analysis than Level 1, but still be accurate enough to trace changes over time. In that case, the restaurant segment would go from 89 quantification days, which can be considered a borderline number, to 2092, which would yield a more precise value for the segment. Schools are on the right track and should continue to do what they are doing at the moment, while other segments might have something to learn from the schools segment, even when they operate under different conditions. The quite large deviations between segments and even between kitchens within the same segment suggest that there is room for improvement and that food waste within the hospitality sector can be decreased.

Author Contributions: Conceptualization, C.M., P.-A.H., I.S. and M.E.; Data curation, C.M., P.C., H.H., O.P., C.S. and M.E.; Formal analysis, C.M.; Resources, C.M., P.C., H.H., O.P., C.S. and M.E.; Writing-original draft, C.M.; Writing-review and editing, C.M., P.C., P.-A.H., H.H., O.P., C.S., I.S. and M.E.

Funding: This research was funded through the H2020 ERA-net Cofund on Sustainable Food Production and Consumption (SUSFOOD2) by the Swedish Research Council for Sustainable Development (Formas), grant number FR-2018/0001, the Finnish Ministry of Agriculture and Forestry grant number 56/03.01.02/2018, the German Federal Ministry of Food and Agriculture (BMEL) through the Federal Office for Agriculture and Food (BLE), grant number 2818ERA07B, and The Research Council of Norway, grant number 284506.

Acknowledgments: The authors would like to thank all the organizations that contributed data to the study, among others several municipalities and regions in Sweden, United against Waste e.V., in Germany and Norwegian and Finnish project partners.

Conflicts of Interest: The authors declare no conflict of interest. The funders had no role in the design of the study; in the collection, analyses, or interpretation of data; in the writing of the manuscript, or in the decision to publish the results.

\section{References}

1. FAO. Global Food Losses and Food Waste-Extent, Causes and Prevention; FAO: Rome, Italy, 2011; ISBN 978-92-5-107205-9.

2. Stuart, T. Waste: Uncovering the Global Food Scandal; W.W. Norton \& Co.: New York, NY, USA, 2009; ISBN 978-0-393-06836-8.

3. Stockholm Resilience Centre Can Increasingly Well-Organised Food Assistance Initiatives Help Improve Struggling Welfare Systems? Stockholm Resilience Centre. Available online: https:/www.stockholmresilience.org/research/research-news/2018-02-15-small-wins-leading-tothe-big-win.html (accessed on 16 November 2018).

4. United Nations. Transforming Our World: The 2030 Agenda for Sustainable Development; United Nations: New York, NY, USA, 2015. 
5. EU Actions against Food Waste. Food Safety. Available online: https://ec.europa.eu/food/safety/food_waste/ eu_actions_en (accessed on 23 May 2019).

6. Tesco. Tesco and Society; Tesco: Hertfordshire, UK, 2014.

7. Springmann, M.; Clark, M.; Mason-D'Croz, D.; Wiebe, K.; Bodirsky, B.L.; Lassaletta, L.; de Vries, W.; Vermeulen, S.J.; Herrero, M.; Carlson, K.M.; et al. Options for keeping the food system within environmental limits. Nature 2018, 562, 519-525. [CrossRef]

8. Diaz-Ruiz, R.; Costa-Font, M.; López-i-Gelats, F.; Gil, J. A Sum of Incidentals or a Structural Problem? The True Nature of Food Waste in the Metropolitan Region of Barcelona. Sustainability 2018, 10, 3730. [CrossRef]

9. FAO. Methodological Proposal for Monitoring SDG Target 12.3 The Global Food Loss Index Design, Data Collection Methods and Challenges; FAO: Rome, Italy, 2018.

10. Hanson, C.; Lipinski, B.; Robertson, K.; Dias, D.; Gavilan, I.; Gréverath, P.; Ritter, S.; Fonseca, J.; van Otterdijk, R.; Timmermans, T.; et al. Food Loss and Waste Accounting and Reporting Standard; WBSCD: Geneva, Switzerland, 2016; p. 160.

11. Boij, A. Mindre matsvinn: Utvärdering av Hushållningssällskapets Nationella Projekt; A. BOIJ AB Idé- och produktutveckling: Tranås, Sweden, 2013; ISBN 978-91-979424-7-8.

12. Vittuari, M.; Azzurro, P.; Gaiani, S.; Gheoldus, M.; Burgos, S.; Aramyan, L.; Valeeva, N.; Rogers, D.; Östergren, K.; Timmermans, T.; et al. Recommendations and Guidelines for a Common European Food Waste Policy Framework; FUSIONS: Bologna, Italy, 2016; ISBN 978-94-6257-959-0.

13. Eriksson, M. Sveriges lantbruksuniversitet Institutionen för Energi och Teknik Supermarket Food Waste: Prevention and Management with the Focus on Reduced Waste for Reduced Carbon Footprint; Swedish University of Agricultural Sciences: Uppsala, Sweden, 2015.

14. Eriksson, M.; Persson Osowski, C.; Malefors, C.; Björkman, J.; Eriksson, E. Quantification of food waste in public catering services-A case study from a Swedish municipality. Waste Manag. 2017, 61, 415-422. [CrossRef]

15. SEPA. Minskat Svinn av Livsmedel i Skolkök: Erfarenheter och Framgångsfaktorer; Naturvårdsverket: Stockholm, Sweden, 2009; ISBN 978-91-620-5979-8.

16. Heikkilä, L.; Reinikainen, A.; Katajajuuri, J.-M.; Silvennoinen, K.; Hartikainen, H. Elements affecting food waste in the food service sector. Waste Manag. 2016, 56, 446-453. [CrossRef]

17. Marthinsen, J.; Sundt, P.; Kaysen, O.; Kirkevaag, K.; Nordic Council of Ministers. Prevention of Food Waste in Restaurants, Hotels, Canteens and Catering; Nordic Council of Ministers: Copenhagen, Denmark, 2012.

18. Lorenz, B.; Hartmann, M.; Hirsch, S.; Kanz, O.; Langen, N. Determinants of Plate Leftovers in One German Catering Company. Sustainability 2017, 9, 807. [CrossRef]

19. Baig, M.B.; Al-Zahrani, K.H.; Schneider, F.; Straquadine, G.S.; Mourad, M. Food waste posing a serious threat to sustainability in the Kingdom of Saudi Arabia-A systematic review. Saudi J. Biol. Sci. 2018. [CrossRef]

20. Byker, C.J.; Farris, A.R.; Marcenelle, M.; Davis, G.C.; Serrano, E.L. Food Waste in a School Nutrition Program After Implementation of New Lunch Program Guidelines. J. Nutr. Educ. Behav. 2014, 46, 406-411. [CrossRef]

21. Barton, A.D.; Beigg, C.L.; Macdonald, I.A.; Allison, S.P. High food wastage and low nutritional intakes in hospital patients. Clin. Nutr. 2000, 19, 445-449. [CrossRef]

22. Sonnino, R.; McWilliam, S. Food waste, catering practices and public procurement: A case study of hospital food systems in Wales. Food Policy 2011, 36, 823-829. [CrossRef]

23. El-Mobaidh, A.M.; Razek Taha, M.A.; Lassheen, N.K. Classification of in-flight catering wastes in Egypt air flights and its potential as energy source (chemical approach). Waste Manag. 2006, 26, 587-591. [CrossRef]

24. Dias-Ferreira, C.; Santos, T.; Oliveira, V. Hospital food waste and environmental and economic indicators-A Portuguese case study. Waste Manag. 2015, 46, 146-154. [CrossRef]

25. Liz Martins, M.; Cunha, L.M.; Rodrigues, S.S.P.; Rocha, A. Determination of plate waste in primary school lunches by weighing and visual estimation methods: A validation study. Waste Manag. 2014, 34, 1362-1368. [CrossRef]

26. Boschini, M.; Falasconi, L.; Giordano, C.; Alboni, F. Food waste in school canteens: A reference methodology for large-scale studies. J. Clean. Prod. 2018, 182, 1024-1032. [CrossRef]

27. Katajajuuri, J.-M.; Silvennoinen, K.; Hartikainen, H.; Heikkilä, L.; Reinikainen, A. Food waste in the Finnish food chain. J. Clean. Prod. 2014, 73, 322-329. [CrossRef]

28. Ferreira, M.; Liz Martins, M.; Rocha, A. Food waste as an index of foodservice quality. Br. Food J. 2013, 115, 1628-1637. [CrossRef] 
29. Liu, Y.; Cheng, S.; Liu, X.; Cao, X.; Xue, L.; Liu, G. Plate Waste in School Lunch Programs in Beijing, China. Sustainability 2016, 8, 1288. [CrossRef]

30. Engström, R.; Carlsson-Kanyama, A. Food losses in food service institutions Examples from Sweden. Food Policy 2004, 29, 203-213. [CrossRef]

31. Falasconi, L.; Vittuari, M.; Politano, A.; Segrè, A. Food Waste in School Catering: An Italian Case Study. Sustainability 2015, 7, 14745-14760. [CrossRef]

32. Betz, A.; Buchli, J.; Göbel, C.; Müller, C. Food waste in the Swiss food service industry-Magnitude and potential for reduction. Waste Manag. 2015, 35, 218-226. [CrossRef]

33. Hansson, E. Matsvinn på Förskolor -En Fallstudie av Kvantiteter och Orsaker i Knivsta Kommun; SLU: Uppsala, Sweden, 2016; p. 39.

34. Ozcicek-Dolekoglu, C.; Var, I. Analysis of food waste in university dining halls: A case study from turkey. Fresenius Environ. Bull. 2019, 28, 156-166.

35. Xue, L.; Liu, G.; Parfitt, J.; Liu, X.; Van Herpen, E.; Stenmarck, Å.; O’Connor, C.; Östergren, K.; Cheng, S. Missing Food, Missing Data? A Critical Review of Global Food Losses and Food Waste Data. Environ. Sci. Technol. 2017, 51, 6618-6633. [CrossRef] [PubMed]

36. WRAP. The Composition of Waste Disposed of by the UK Hospitality Industry; WRAP: Banbury, UK, $2011 ;$ p. 129.

37. Matsvinnsmätning i Storkök. Available online: https://www.livsmedelsverket.se/matvanor-halsa--miljo/ maltider-i-vard-skola-och-omsorg/matsvinnmatning-i-storkok (accessed on 17 January 2019).

38. Eriksson, M.; Persson Osowski, C.; Björkman, J.; Hansson, E.; Malefors, C.; Eriksson, E.; Ghosh, R. The tree structure-A general framework for food waste quantification in food services. Resour. Conserv. Recycl. 2018, 130, 140-151. [CrossRef]

39. Eriksson, M.; Lindgren, S.; Persson Osowski, C. Mapping of food waste quantification methodologies in the food services of Swedish municipalities. Resour. Conserv. Recycl. 2018, 137, 191-199. [CrossRef]

40. Steen, H.; Malefors, C.; Röös, E.; Eriksson, M. Identification and modelling of risk factors for food waste generation in school and pre-school catering units. Waste Manag. 2018, 77, 172-184. [CrossRef] [PubMed]

41. Strotmann, C.; Friedrich, S.; Kreyenschmidt, J.; Teitscheid, P.; Ritter, G. Comparing Food Provided and Wasted before and after Implementing Measures against Food Waste in Three Healthcare Food Service Facilities. Sustainability 2017, 9, 1409. [CrossRef]

42. Finnish National Agency for Education School meals in Finland 2012. Available online: https://www.oph.fi/ english/current_issues/101/0/free_school_meals_a_finnish_innovation (accessed on 26 June 2019).

43. Regeringskansliets Rättsdatabaser. Available online: http://rkrattsbaser.gov.se/sfst?bet=2010:800 (accessed on 25 January 2019).

44. Swedish National Food Agency. Guidelines for Primary Schools, Secondary Schools and Youth Recreation Centres; Livsmedelsverket: Uppsala, Sweden, 2013; ISBN 978-91-7714-220-1.

45. Clapham, C.; Nicholson, J. The Concise Oxford Dictionary of Mathematics, 4th ed.; Oxford paperback reference; Oxford University Press: Oxford, UK, 2009; ISBN 978-0-19-923594-0.

46. Eriksson, M.; Malefors, C.; Björkman, J.; Eriksson, E. Matsvinn i Storkök—En Kvantitativ Fallstudie Från Sala Kommun; SLU: Uppsala, Sweden, 2016; p. 32.

47. Silvennoinen, K.; Heikkilä, L.; Katajajuuri, J.-M.; Reinikainen, A. Food waste volume and origin: Case studies in the Finnish food service sector. Waste Manag. 2015, 46, 140-145. [CrossRef] [PubMed]

48. Swedish National Food Agency Matsvinnsmätning iStorkök. Available online: https://www.livsmedelsverket. se/matvanor-halsa--miljo/maltider-i-vard-skola-och-omsorg/matsvinnmatning-i-storkok (accessed on 21 March 2019).

49. Hartikainen, H.; Riipi, I.; Katajajuuri, J.-M.; Silvennoinen, K. From measurement to management: Food waste in the Finnish food chain. In Food Waste Management: Solving the Wicked Problem; Palgrave Macmillan: Basingstoke, UK, 2019.

(C) 2019 by the authors. Licensee MDPI, Basel, Switzerland. This article is an open access article distributed under the terms and conditions of the Creative Commons Attribution (CC BY) license (http://creativecommons.org/licenses/by/4.0/). 